\title{
CORRESPONDENCE
}

\section{Blueprint for Survival}

SIR,- "Blueprint for Survival" attempts, at some length, to set out the facts of the present world situation with regard to population, resources and environment. It then goes on to make a number of predictions based on current trends and socio-political attitudes. Its signatories, although they may not agree with every point of detail, are convinced that the assessment it contains is substantially correct. We also believe that its suggestions for reversing some of the more obviously damaging trends are sensible.

You accuse The Ecologist and the signatories of reflecting many of the "half-baked anxieties about what is called the environmental crisis" and go on to suggest that "the forces which have made civilized societies more humane" will overcome our problems (Nature, 235, 63 ; 1972).

It is surely your duty, both to the scientific community and to the society at large, to marshal and present in extenso the evidence which leads you to dismiss the arguments in "Blueprint for Survival".

Yours faithfully,

Aubrey Manning

Department of Zoology,

West Mains Road, Edinburgh EH9 3JT

1 The Ecologist, 2, 1 (1972).

SIR,- The leading article in Nature entitled "The Case against Hysteria" (Nature, 235, 63 ; 1972) does little credit to a distinguished journal, from which one expects impartial and well balanced assessments of scientific and social problems. Those who are criticized for the views they advance may have overstated their case at times, but such overstatements are the result of their awareness of the urgency of the problem that faces mankind (not just Britain) if population growth is not checked in the next few decades. You, Sir, appear to think that the problem will cease to exist if you bury your head in the sand. A more constructive discussion of these problems in your columns would be very welcome.

Yours faithfully,

\section{S. R. J. WOODELL}

Botany School, South Parks Road, Oxford $O X 13 R A$

\section{Improving the Turkey}

SIR,-The leading article in the Christmas Nature $(234,429 ; 1971)$ focused the essential problem raised by the Rothschild Report on to the timely question: "Is it feasible to think of developing Christmas turkeys weighing substantially more than those on the market and, if so, what kind of research programme would be necessary and how much would it cost?" Now members of the staff of my laboratory did almost exactly that a few years ago. Not quite exactly, because the problem is not so much to increase total weight until the bird is too big for modern ovens or less philoprogenitive families, but to get it to a suitable weight with as little input of food as possible, and with its weight concentrated in the most desirable part, the breast (over-portly males find difficulty in copulating, and the only way round this difficulty lay in the development of satisfactory methods of artificial insemination). The story of how the research was actually organized is perhaps worth telling because it provides a concrete example of the inadequacy of either the Rothschild or Dainton proposals.

One and perhaps the most important factor in the recent "industrialization" of large scale production of poultry, including turkeys, has been development of systems of breeding and testing lines which will be crossed to produce the actual birds which will be sold as carcasses or egg layers. These systems are based on general genetic principles, but the efficiency of a firm depends critically on how well it can squeeze the last few per cent out of the output/food input ratio. In the early days of the industrialization, the situation was highly competitive; this phase has now been replaced by one of worldwide mergers. In the mid-fifties, a turkey breeder asked the ARC to advise him on his genetics. I have forgotten whether it was the then Secretary (Sir William Slater) or the then President (Lord Rothschild) who asked me to get one of the people in my ARC Unit to look into the question; but at any rate the Research Council set-up worked satisfactorily as an "indirect customer" at the first stage. But it soon became clear that we could not get the detailed information necessary without entering into a relation of confidentiality. When the ARC were consulted, they regretfully came to the conclusion that they could not allow one of their staff to advise one turkey breeder out of the many on a basis of confidentiality, since they would not have enough trained staff if his competitors put their claim for similar official assistance. Even less could the ministry become closely enough associated with the details of the production process in a particular firm. The kind of operation which the ministry could undertake is exemplified by its Poultry Stock Improvement Plan, which involved building four large strain-testing stations in various parts of the country at a cost of at least $£ 2$ million; when the scheme turned out to be a disastrous failure (owing to lack of proper genetical advice) this investment had to be, to all intents and purposes, written off.

The only solution, if we were not to drop the turkey project entirely-and it offered too many intellectually interesting problems for that to be acceptable, even if we paid no attention to the economics -was to arrange a swap of posts between the university departmental staff and the staff of the ARC Unit. The turkey geneticist took a university lectureship, at considerably reduced salary, but with the normal permission to engage in paid consultant work to a limit which was deemed not to interfere with his duties as a university teacher. A few years later this turkey firm became the centre of a large amalgamation and now forms the nucleus of one of the largest turkey breeding organizations in the world*; and the turkey geneticist was asked by the Ministry to write their official handbook on turkey breeding. The total cost to the country was one lecturer-level salary (which would have had to be paid anyway, even if the man had not worked on turkeys).

So all ended on a suitably Christmassy note. But there are two morals in connexion with the Green Paper. The first is that the real "customer" is usually the actual producer, and not the ministry as Rothschild suggests; in fact neither the ministry nor even the less encumbered research council can represent the customer in the full detail which may be necessary. The second is that even the ultimate customer often does not know at all concretely what it is that he is afterthe turkey breeder only knew that he wanted to improve his stock, not that he had to set up an elaborate system of line breeding, crossing and testing. To tell him that, he needed a "contractor" who could enter into a confidential professional relationship.

Yours faithfully, C. H. WADDINGTON

Institute of Animal Genetics,

West Mains Road, Edinburgh EH9 $3 J N$

* They can produce big turkeys, too. I think they still hold the world record with something over $65 \mathrm{lb}$. If the Editor of Nature wants their address before next Christmas, I shall be happy to supply it. 